\title{
Botulinum Toxin in the Surgical Treatment of Complex Abdominal Hernias: A Surgical Anatomy Approach, Current Evidence and Outcomes
}

\author{
FOTIOS SERETIS, DIMOSTHENIS CHRYSIKOS, ALEXANDROS SAMOLIS and THEODORE TROUPIS
}

\author{
Department of Anatomy, School of Medicine, National and Kapodistrian University of Athens, Athens, Greece
}

\begin{abstract}
Background/Aim: Abdominal wall hernias represent a common problem in surgical practice. A significant proportion of them entails large defects, often difficult to primarily close without advanced techniques. Injection of botulinum toxin preoperatively at specific points targeting lateral abdominal wall musculature has been recently introduced as an adjunct in achieving primary fascia closure rates. Materials and Methods: A literature search was conducted investigating the role of botulinum toxin in abdominal wall reconstruction focusing on anatomic repair of hernia defects. Results: Injecting botulinum toxin preoperatively achieved chemical short-term paralysis of the lateral abdominal wall muscles, enabling a tension-free closure of the midline, which according to anatomic and clinical studies should be the goal of hernia repair. No significant complications from botulinum injections for complex hernias were reported. Conclusion: Botulinum is a significant adjunct to complex abdominal wall reconstruction. Further studies are needed to standardize protocols and create more evidence.
\end{abstract}

Abdominal wall hernias represent a common problem in current surgical practice. Over $20 \%$ of all abdominal operations performed in the US annually are complicated by development of an incisional hernia (1). In an attempt to identify the key players in the successful treatment of the most challenging subgroup of these hernias, namely the complex hernias, a scheme identifying size and location,

This article is freely accessible online.

Correspondence to: Professor Theodore Troupis, Department of Anatomy, School of Medicine, Faculty of Health Sciences, National and Kapodistrian University of Athens, 75 Mikras Asias str., Goudi, 11527 Athens, Greece. Tel: +30 2107462388, Fax: +30 2107462398 , e-mail: ttroupis@med.uoa.gr

Key Words: Botulinum toxin, abdominal wall hernias, surgical repair, review. contamination and soft tissue infection as well as patient history and risk factors has been proposed (2). Incisional hernias are well known to recur after repair (3), thus underlying the importance of solid knowledge of relevant anatomy, technique and most importantly new adjuncts in treatment. More advanced techniques in hernia repair were developed such as Rives-Stoppa retro-rectus repair and, subsequently, posterior components separation whith the goal to achieve primary and tension-free myo-fascial closure reinforced by mesh placement (4). The goal of this study was to review current evidence regarding the use of botulinum toxin in the treatment of abdominal wall hernia repair, in a critical manner.

\section{Materials and Methods}

The protocol of this review has been submitted to the Institutional Review Board of Department of Anatomy, National and Kapodistrian University of Athens, Greece and is available upon request. Eligible articles were identified by search of the Medline Embase, Cinahl and Google Scholar bibliographical databases for the period from 2010 up to March 2021. The study protocol was agreed by all co-authors. The search strategy included the following keywords: "botulinum toxin/botox AND hernia repair/incisional hernia/component separation". Further search terms that were used were "chemical components separation AND hernia", "loss of domain AND hernia", "complex abdominal wall hernia", "abdominal wall reconstruction", "progressive preoperative pneumoperitoneum AND hernia".

Study selection criteria. Language restrictions were applied (only articles in English, French and German were considered eligible); two investigators (FS and DC), working independently, searched the literature and extracted data from each eligible study. Reviews and case reports were excluded, while all prospective and retrospective studies, were eligible for this review. Articles that did not state the names of the authors were excluded. Studies with less than 15 patients were also excluded. All references from the manuscripts retrieved with the aforementioned search strategy were manually searched for additional information. Also, as part of our review we have searched for studies on abdominal wall anatomy and therefore 
terms such as "abdominal wall anatomy AND hernia" were used in the literature search. The focus was on retrieving data from basic science, experimental models, studies on outcomes using the various surgical techniques and comparative data in an attempt to establish an integrated approach to complex abdominal wall reconstruction.

Study selection. The search strategy retrieved 6,757 articles, 60 of these were considered eligible and possible sources from the title and abstract presented. The other articles were excluded (by applying exclusion criteria) and finally 13 of them were selected to be included in this literature review.

\section{Results}

Complex abdominal wall reconstruction requires reapproximation of fascia to achieve primary closure of the defect in a tension-free manner to recreate normal abdominal wall anatomy (5). Previous evidence has demonstrated that patients with midline incisional hernias suffer from abdominal wall dysfunction not due to muscle dysfunction per se, due to the existence of the hernia, but rather because of altered anatomy as a result of lateralization of abdominal wall musculature and resultant loss of midline insertion into the linea alba of the aforementioned muscles (6-7). The laterally-directed pulling forces of abdominal wall muscles is one of the main mechanisms of gradual enlargement of an abdominal wall defect over time (8). Recreation of anatomy thus leads to functional regaining (9). The superiority in terms of complication and recurrence rates of myo-fascial closure with mesh reinforcement over bridged repair for large ventral hernias has been well documented in the literature as well (10-11). The altered anatomy has been shown in a rat model of midline incisional hernias to lead to different distribution of mechanical forces on abdominal wall musculature and decreased compliance, namely the internal oblique muscles developed a histological pattern consistent with atrophic changes (change in the distribution of muscle fibers, decreased cross-sectional area and pathologic fibrosis), thus transferring the load of forces onto the midline (12). In another report from Lien et al. with data from a rat model of incisional hernia, partial paralysis of abdominal wall muscles with botulinum toxin reduced both the number and size of incisional hernias (13). The authors concluded that it was the negation of outwards-and-laterally oriented contractile forces, which had a beneficial effect on midline herniation process after laparotomy. Re-approximation of rectus abdominii muscles in a suture-only repair, interestingly, improved isokinetic strength of trunk flexors when compared to mesh-only repair without defect closure (14). More complex reconstruction techniques more likely owe their success to restoration of normal anatomy as demonstrated by Lisiecki et al. (15). They described in their report changes in the dimensions of the entire abdomen after component separation but no changes in the fascial area.
These concepts are further elucidated by an interesting report with long-term follow-up of abdominal wall reconstruction after planned ventral hernia encompassing 152 patients, which reports a 5 percent rate of hernia recurrence in patients offered abdominal wall reconstruction with components separation without mesh reinforcement (16).

Based on the aforementioned data, it has been theorized that chemical paralysis of lateral abdominal wall musculature could be a valuable adjunct in the repair of complex abdominal wall hernias. Botulinum toxin A acts a neuro-modulating agent that blocks the release of acetylcholine and other pain modulating substances to induce flaccid paralysis with the maximum effect reached in 3 weeks and lasting up to 3-6 months after injection (17). Zielinski et al. reported on their experience with 18 patients with abdominal wall defects associated with open abdomen. Botulinum toxin despite being used much earlier than its optimum timing of peak action, resulted in $83 \%$ primary fascial closure and a $6 \%$ partial fascial closure with no added morbidity and most importantly cancelling the need for the more morbid surgical components separation in this critically ill patient population (18). Another research paper (19) reported on 17 patients with incisional hernias after open abdomen and described that the administration of botulinum toxin under ultrasound guidance at a dose of 50 units at each of the 5 injection points on each side, resulted after 4 weeks in significant decreases in lateral abdominal muscle thickness as well as significant increases in length, thus reversing the process of their atrophy/lateralization described above. Muscle length gain was reported at a mean of 2.59 and $2.44 \mathrm{~cm}$ per side respectively for a total of almost $5 \mathrm{~cm}$ of possible gain in defect coverage due to lateral advancement on each side. Due to the pain modulating properties of botulinum toxin as well, a significant reduction in pain scores and opioid analgesia requirements after incisional hernia repair, has also been reported in patients undergoing 'chemical component paralysis' (20). Interestingly, in the same research paper no increase in pulmonary complications was noted according to the authors, thereby providing an answer about the theoretical risks of lateral abdominal wall muscle paralysis which are known to act as accessory respiratory muscles. A cumulative table has been created with details on the protocol of administration as well as adverse effects noted is available in Table I.

Apart from the few reports on abdominal wall reconstruction after open abdomen, there is an increasing body of literature on the use of botulinum toxin in abdominal wall reconstruction in complex incisional hernias and especially in hernias with loss of domain. In 2009 the European Hernia Society (EHS) developed a classification scheme for primary and incisional abdominal hernias (21) which describes what constitutes a large hernia defect as well as loss of domain hernia (LODH). As described by Tanaka et al. (22), a computed tomography-facilitated measurement of the ratio of the volume of incisional hernia sac and the 
Table I. Protocol of administration, site of injection, dosage and adverse effects from injection. First column shows the relevant studies. The second column includes the number of patients. The third column shows the Units $(U)$ of botulinum injected and the localizing method used for identifying the site. The fourth column shows the complications from the injection reported in each study.

\begin{tabular}{|c|c|c|c|c|}
\hline Study & $\begin{array}{c}\text { Number of } \\
\text { patients }\end{array}$ & $\begin{array}{l}\text { Protocol for } \\
\text { injection }\end{array}$ & $\begin{array}{c}\text { Site of } \\
\text { injection }\end{array}$ & Complications \\
\hline Zielinski et al. 2013 (18) & 18 & $\begin{array}{l}\text { Total of } 300 \mathrm{U} \text { of botox under } \\
\text { ultrasound guidance }(150 / \text { side })\end{array}$ & $\begin{array}{c}\text { Internal oblique } \\
\text { external oblique } \\
\text { transversus abdominis } \\
\text { ( } 3 \text { points } / \text { side })\end{array}$ & $\begin{array}{l}\text { None related to } \\
\text { botox injection }\end{array}$ \\
\hline $\begin{array}{l}\text { Ibarra-Hurtado et al. } \\
2013 \text { (19) }\end{array}$ & 17 & $\begin{array}{c}\text { Total of } 500 \mathrm{U} \text { under } \\
\text { ultrasound guidance }(250 / \text { side })\end{array}$ & $\begin{array}{l}\text { External oblique+ } \\
\text { internal oblique } \\
\text { (5 points/side })\end{array}$ & $\begin{array}{l}\text { None related to } \\
\text { botox injection }\end{array}$ \\
\hline Zendejas et al. 2013 (20) & 22 & $\begin{array}{l}\text { Total of } 300 \mathrm{U} \text { of botox } \\
\text { under ultrasound guidance }(150 / \text { side })\end{array}$ & $\begin{array}{l}\text { Internal oblique } \\
\text { external oblique } \\
\text { transversus abdominis } \\
\text { ( } 3 \text { points/side })\end{array}$ & $\begin{array}{l}\text { None related to } \\
\text { botox injection }\end{array}$ \\
\hline Nielsen et al. 2020 (40) & 37 & $\begin{array}{l}\text { Total of } 300 \mathrm{U} \text { of botox under } \\
\text { ultrasound guidance }(150 / \text { side })\end{array}$ & $\begin{array}{c}\text { Internal oblique } \\
\text { external oblique } \\
\text { transversus abdominis } \\
(3-5 \text { points/side })\end{array}$ & $2.7 \%$ pain reported \\
\hline Elstner et al. 2020 (42) & $\begin{array}{c}46 \text { (23 3-layer } \\
\text { intramuscular } \\
\text { injection } v s . \\
23 \text { 2-layer injection) }\end{array}$ & $\begin{array}{c}\text { Total of } 200 \mathrm{U} \text { of botox } \\
\text { under ultrasound guidance } \\
(100 / \text { side })\end{array}$ & $\begin{array}{l}\text { (internal+external oblique) } \\
100 \% \text { of patients+transversus } \\
\text { abdominis } 50 \% \text { of patients }\end{array}$ & $\begin{array}{l}\text { No data available } \\
1 \text { patient reported } \\
\text { with dyspnea }\end{array}$ \\
\hline $\begin{array}{l}\text { Catalán-Garza et al. } \\
2020 \text { (43) }\end{array}$ & 36 & $\begin{array}{c}\text { Total of } 300 \mathrm{U} \text { of botox } \\
\text { under ultrasound guidance } \\
(150 / \text { side }) \\
250 \text { units in parastomal hernias }\end{array}$ & $\begin{array}{c}\text { Internal oblique } \\
\text { external oblique } \\
\text { transversus abdominis } \\
(3 \text { points/side }) \\
5 \text { points in parastomal hernia }\end{array}$ & $\begin{array}{l}\text { None related to } \\
\text { botox injection }\end{array}$ \\
\hline
\end{tabular}

volume of abdominal cavity over $25 \%$ constitutes loss of domain and is predictive of a traumatic reduction of the hernia contents inside abdominal cavity. This concept is further elaborated by the C. Sabbagh et al. report in 2011 (23), where it was concluded that a ratio of (incisional hernia volume) divided by the (peritoneal volume) resulting in less than $20 \%$ predicts a tension-free primary fascial closure. In their report, they used progressive preoperative pneumoperitoneum (PPP) as a 'neoadjuvant' adjunct prior to repair of complex incisional hernias based as previously described extensively (24-25). It is of great value, in our opinion, to notice that progressive preoperative pneumoperitomeum increases the abdominal wall muscle length and has the same impact in the incisional hernia orifice (26) and, even more interestingly, it causes an increase in the volume of hernia sac and abdominal cavity to the same extent, thus leaving the volume of incisional hernia/volume of abdominal (VIH/VAC) cavity ratio unchanged (27). It is exactly this key point where injection of botulinum toxin might play a key role, because injection into the muscles leaves essentially the dimensions of the incisional hernia sac unchanged and changes only the dimensions of the abdominal wall cavity. A research paper from Lledo et al. from 2018
(28) confirms this concept. The authors report on their experience on 70 patients with loss of domain hernias and by using a CT volumetric protocol document that the combination of PPP and botulinum toxin decreases the VIH/VAC ratio as well as the hernia defect diameters, which both constitute a key factor in the treatment of LODH.

Apart from the 'chemical components separation' with botulinum toxin, mechanical and/or surgical disruption of abdominal wall muscles and fasciae with position of meshes has evolved with techniques such as the Rives-Stoppa retromuscular repair and the more extensive anterior components separation as well as posterior components separation with or without transverse abdominis release (29). Adding anterior or posterior components separation to a Rives-Stoppa facilitates further medial advancement at the cost of extra dissection (30). Disruption of the vascular perforators during anterior components separation may account for the higher rate of wound complications of this method compared to posterior components separation, as confirmed in a study catching data over 12 years on 775 patients (31). Increasingly nowadays, abdominal wall reconstruction is performed in contaminated fields (32) and in a patient population with co-morbidities of increasing 
Table II. Studies with available data on hernia defect size, surgical technique used and rate of primary fascial closure achievement rate. First column shows the studies which include data on hernia defect size, number of patients, surgical method used and primary fascial approximation rate. The second column shows the type of study included. Third column shows the number of patients and the fourth column the type of defect. The fifth column includes data on defect size expressed in centimeters $(\mathrm{cm})$ or square centimeters $\left(\mathrm{cm}^{2}\right)$. The sixth column shows the type of repair performed and the seventh column the rate of primary fascial approximation achieved. *Highlights that in one study included in the table, botulinum toxin was combined with progressive preoperative pneumoperitoneum.

\begin{tabular}{|c|c|c|c|c|c|c|}
\hline Study & $\begin{array}{l}\text { Type of } \\
\text { study }\end{array}$ & $\begin{array}{l}\text { Number of } \\
\text { patients }\end{array}$ & $\begin{array}{l}\text { Type of } \\
\text { defect }\end{array}$ & $\begin{array}{l}\text { Defect } \\
\text { size }\end{array}$ & $\begin{array}{l}\text { Type of } \\
\text { repair }\end{array}$ & $\begin{array}{l}\text { Outcomes } \\
\text { (primary } \\
\text { closure rate) }\end{array}$ \\
\hline $\begin{array}{l}\text { Zielinski et al. } \\
2013 \text { (18) }\end{array}$ & Retrospective & 18 & Open abdomen & Not applicable & $\begin{array}{l}\text { Primary fascial } \\
\text { closure }\end{array}$ & $83 \%$ \\
\hline $\begin{array}{l}\text { Ibarra-Hurtado } \\
\text { et al. } 2013 \text { (19) }\end{array}$ & Clinical trial & 17 & $\begin{array}{l}\text { Hernia secondary } \\
\text { to open abdomen } \\
\geq 12 \text { months ago }\end{array}$ & $\begin{array}{c}14.65 \mathrm{~cm} \text { mean } \\
\text { value of transverse } \\
\text { diameter }\end{array}$ & $\begin{array}{c}9 \text { component separation } \\
4 \text { Rives repair } \\
4 \text { Primary closure }\end{array}$ & $100 \%$ \\
\hline $\begin{array}{l}\text { Zendejas et al. } \\
2013 \text { (20) }\end{array}$ & $\begin{array}{l}\text { Retrospective } \\
\text { case control study }\end{array}$ & 22 & Incisional hernia & $\begin{array}{c}59.7 \mathrm{~cm}^{2} \text { hernia } \\
\text { defect median value }\end{array}$ & $\begin{array}{l}100 \% \text { underlay } \\
\text { mesh repair }\end{array}$ & $41 \%$ \\
\hline $\begin{array}{l}\text { Bueno-Lledó } \\
\text { et al. } 2018 \text { (28) }\end{array}$ & $\begin{array}{c}\text { Observational study } \\
\text { *botulinum combined } \\
\text { with progressive } \\
\text { preoperative } \\
\text { pneumoperitoneum }\end{array}$ & 70 & $\begin{array}{l}\text { Incisional hernia } \\
\text { with loss of domain }\end{array}$ & $\begin{array}{c}16.9 \mathrm{~cm} \text { longitudinal } \\
\times 17 \mathrm{~cm} \text { transverse } \\
\text { (diameters-median } \\
\text { values) }\end{array}$ & $\begin{array}{c}77 \% \text { anterior } \\
\text { component } \\
\text { separation } \\
20 \% \text { transverse } \\
\text { abdominis release } \\
2.9 \% \text { Rives-Stoppa }\end{array}$ & $95.7 \%$ \\
\hline $\begin{array}{l}\text { Deerenberg et al. } \\
2021 \text { (39) }\end{array}$ & Comparative study & 75 & $\begin{array}{l}\text { Ventral hernia } \\
\text { with loss of domain }\end{array}$ & $\begin{array}{c}251 \mathrm{~cm}^{2} \text { average size } \\
\text { of hernia defect }\end{array}$ & $\begin{array}{l}61 \% \text { component } \\
\text { separation }\end{array}$ & $92 \%$ \\
\hline $\begin{array}{l}\text { Elstner et al. } \\
2020(42)\end{array}$ & $\begin{array}{l}\text { Prospective } \\
\text { observational }\end{array}$ & 46 & Ventral hernia & $\begin{array}{c}11.3 \mathrm{~cm} \text { mean transverse } \\
\text { diameter of defect }\end{array}$ & $\begin{array}{l}\text { Laparoscopic } \\
\text { repair }\end{array}$ & $100 \%$ \\
\hline $\begin{array}{l}\text { Catalán-Garza } \\
\text { et al. } 2020 \text { (43) }\end{array}$ & Retrospective & 36 & $\begin{array}{l}\text { Ventral hernia } \\
\text { with loss of domain }\end{array}$ & $\begin{array}{c}139.44 \mathrm{~cm} \text { transverse } \\
\text { diameter }\end{array}$ & $\begin{array}{c}75 \% \text { anterior } \\
\text { component separation } \\
25 \% \text { no additional technique }\end{array}$ & $78 \%$ \\
\hline
\end{tabular}

complexity, such as increasing body mass index (BMI), which has been shown to independently increase wound complication rate (33). Limiting disruption of vasculature as well as reducing the degree of dissection might, therefore, be of value, which is perhaps why endoscopic anterior component separation appears to have lower wound complication rates compared to the open technique (34). To add more to the problem, evidence exists that increasing BMI is correlated with decreased density of major deep inferior epigastric perforators (35). More interestingly, repair of large incisional hernias with achievement of primary fascial closure without components separation appears to yield similar hernia recurrence rates but significantly lower wound infection rates compared to primary fascial closure with use of components separation (36). In this cohort of patients, similarly low rates of bridging $1.8 \%$ in the no-component separation group and $2.7 \%$ in the components separation group were reported, suggesting that it is the achievement of midline recreation in a tension-free manner that is the key driver for hernia recurrence prevention. In our opinion, this is exactly where preoperative chemical components separation using botulinum might play a key role. Lledo et al. (37) published in 2020 their experience from a comparative study on 80 patients with midline incisional hernias, in which chemical components separation down-staged the required hernia repair type from components separation to a Rives-Stoppa repair with a $100 \%$ primary fascial closure achievement rate in the chemical components group and no complications from the injection of botulinum per se. Interestingly, large midline incisional hernias (hernia W3 according to EHS classification) with defects of $12-18 \mathrm{~cm}$ in diameter were only included in the study (21). The comparison group in this study underwent formal components separation with an increased rate of wound complications and in the follow-up period of 19 months it was the only group of patients that experienced hernia recurrence.

Examining the outcomes of use of botulinum toxin (BTA) in abdominal wall reconstruction, Deerenberg et al. (38) reported on a cohort of 108 patients with large incisional hernias with loss of domain that underwent preoperatively botulinum injection under Computer Tomography fluoroscopic or ultrasound guidance. No complications from the injection were reported. Primary fascial closure was achieved in $91 \%$ of patients. Another report from the same research group on massive ventral hernias with loss of domain, compared patients receiving BTA preoperatively to patients not receiving and demonstrated a significantly higher primary fascial closure 
Table III. Summary, in a narrative fashion, of the most important studies on the field of chemical components separation.

\begin{tabular}{|c|c|c|}
\hline Study & Study description & Outcomes-Usefullness for the reader \\
\hline $\begin{array}{l}\text { Bueno-Lledó et al. } \\
2018 \text { (28) }\end{array}$ & $\begin{array}{l}\text {-Observational study encompassing } 70 \text { patients } \\
\text { with loss of domain hernias. Combination of progressive } \\
\text { preoperative pneumoperitoneum and botulinum toxin to } \\
\text { enable reduction in volume of incisional hernial/ } \\
\text { volume of abdominal cavity (VIH/VAC) ratio }\end{array}$ & $\begin{array}{l}\text {-VIH/VAC ratio reduction to successfully achieve } \\
\text { anatomic repair in loss of domain hernias } \\
\text {-Large study group } \\
\text {-Use of botulinum with other modalities preoperative }\end{array}$ \\
\hline $\begin{array}{l}\text { Bueno-Lledó et al. } \\
2020 \text { (37) }\end{array}$ & $\begin{array}{l}\text {-Comparative study encompassing } 80 \text { patients with } \\
\text { large midline incisional hernias with similar hernia defect sizes } \\
40 \text { received preoperative botulinum injection } \\
\text { and has Rives repair } \\
40 \text { patients underwent component separation }\end{array}$ & $\begin{array}{l}\text {-Proof of concept that preoperative botulunum injection } \\
\text { can downstage a surgical repair from a morbid } \\
\text { components separation to Rives retromuscular repair }\end{array}$ \\
\hline $\begin{array}{l}\text { Deerenberg et al. } \\
2021 \text { (39) }\end{array}$ & $\begin{array}{l}\text { Propensity scored matched study } \\
145 \text { patients undergoing abdominal wall reconstruction } \\
\text { versus } 75 \text { patients undergoing abdominal wall } \\
\text { reconstruction with botulinum injection preoperatively }\end{array}$ & $\begin{array}{c}\text {-Large study groups } \\
\text {-Fascial approximation rates as outcome }\end{array}$ \\
\hline $\begin{array}{l}\text { Deerenberg et al. } \\
2021 \text { (41) }\end{array}$ & $\begin{array}{l}\text { Review of techniques of injection of botulinum } \\
\text { in abdominal wall reconstruction }\end{array}$ & $\begin{array}{l}\text {-Excellent review on technical aspects of } \\
\text { chemical components separation } \\
\text {-Detailed review of anatomic points of injection } \\
\text {-Review of protocols used for administration }\end{array}$ \\
\hline
\end{tabular}

rate and comparable recurrence rates, which were mostly associated with failure to achieve fascial approximation (39). Safety profile of preoperative botulinum injection has been well reported with only pain usually expressed only in a minority of patients (40). Injection is most commonly performed under ultrasound guidance usually at the external and internal oblique muscles and in some case series at the transversus abdominis muscle as well. Protocols for the injection have been described in the literature and summarized in a recent review (41). Injection at the transversus abdominis muscle site can safely be spared without compromising abdominal wall length gain after the intervention, thus preserving this muscle which plays a critical role in trunkal stability and normal abdominal wall physiology (42). Longterm results from 36 patients report a $77.8 \%$ fascial approximation achievement rate with the use of botulinum toxin preoperatively and also report a $11.4 \%$ recurrence rate in a 2-year follow-up period with half of the recurrences occurring in the subgroup of patients in which no fascial closure had been accomplished at the time of hernia repair (43). In a systematic review published in 2020 by Wegdam et al. (44), including 14 studies and 377 patients in total with a hernia defect width at a median of $12 \mathrm{~cm}(10-15 \mathrm{~cm})$, a lateral abdominal wall muscle elongation of $4.0 \mathrm{~cm}$ per side was reported, with a $100 \%$ primary fascial closure rate achieved and reported need for component separation in $38 \%$ of patients. However, the authors also concluded that the level of evidence remains low and went on to introduce the term 'abdominal wall prehabilitation'. Apart from the open hernia repair applications of botulinum injection, preoperative handling has been harnessed in laparoscopic techniques as well. Elstner et al. reported on 32 patients from a prospective observational study of patients with a mean fascial defect of $12.3 \mathrm{~cm}$ that underwent laparoscopic repair of their hernias with a $100 \%$ reported fascial closure rate after preoperative botulinum injection (45). A summary of primary fascial closure achievement rate is shown in Table II, where studies included encompass more than 15 patients and the technique used as well as measurements of the hernia defect are described in detail. Table III summarizes key studies on chemical components separation, highlighting the most important relevant concepts as well as the protocols used for administration, according to our opinion.

\section{Discussion}

Abdominal wall reconstruction techniques have recently made tremendous progress. We, hereby, report on the use of botulinum toxin preoperatively as "preconditioning" adjunct of abdominal wall musculature prior to hernia repair. Repair of large incisional hernias with achievement of primary fascial closure seems to restore normal anatomy and physiology and reverse the process of lateral retraction and fibrosis of the lateral abdominal wall muscles compared to simply bridging the hernia defect, now is quantifiable and measurable with radiographic methods (46). In terms of necessitating for "bridging the defect" no significant difference has been identified in a meta-analysis comparing anterior components separation and posterior components separation with transversus abdominis release (47). Chemical components separation technique using botulinum toxin results in a significant gain in abdominal wall muscle length 
that can facilitate achievement of fascial closure at the future repair. More interestingly, it causes a change in the abdominal cavity compliance and therefore relieves tension from midline, thereby potentially reducing the rate of hernia recurrence and avoiding postoperative complications from the reduction of abdominal contents inside the abdominal cavity. In essence, it is a form of prehabilitation of the abdominal wall to accommodate in the near future the herniated contents. Moreover, potential benefits on patient pain as well as reduction in postoperative respiratory adverse sequelae can be expected as well, and this is a field in our opinion worth of further investigation in future studies. Other forms of pre-operative prehabilitation such as the progressive preoperative pneumoperitoneum (PPP) have been described as well, but this modality acts to enlarge both the abdominal cavity volume and the hernia sac volume. In contrast, botulinum injection can be performed selectively in the abdominal wall muscles as an outpatient procedure rather than the cumbersome PPP that is also associated with complications (48). Injection is most commonly performed 30 days prior to hernia repair to reach maximum effect and the available literature concurs that it is a safe procedure with minimal complications and it should be performed under radiologic guidance, usually ultrasound. Further investigating whether the transversus abdominis can be spared in what has been called a "2 layer versus 3 layer" injection technique, could be an area of active research.

After extensively reviewing the literature and in an attempt to critically synthesize the available data, we have come to strongly believe that an area of future research will be to tailor the procedure to the type of hernia and the patient. A detailed anatomic study of abdominal wall anatomy in ventral hernias using imaging modalities (mainly computed tomography) is a key step in the process (49-50). Based on the knowledge that preoperative botulinum injection appears to enable medial advancement of almost $4 \mathrm{~cm}$ per side on average, its application could be of tremendous importance in planning of hernia repair. This should be combined with the knowledge on the medial advancement gain using component separation techniques (51) to allow for a holistic and personalized approach in hernia repair. Therefore, selective chemical components separation protocols as an add-on to or even an alternative in small hernia defects (thus avoiding the morbid dissection of components separation or downsizing the defect enabling repair with less disruptive techniques) might be a reasonable approach. The literature at present as underlined in the systematic review cited above has generated evidence of low level, and thus further studies are needed. Techniques need to be further standardized and refined. However, the concepts entailed in chemical components separation present great interest and will probably become an important weapon in the surgeon's armamentarium against a complex yet quite common problem, as complex hernia is.

\section{Conclusion}

Injection of botulinum toxin pre-operatively at the lateral abdominal wall muscles facilitates medial advancement of the hernia defect edges during elective repair and is associated with high rates of primary fascia closure rates. No major complications have been reported so far from injection. An area of research, in our opinion, might be the selection of patients that may benefit the most, with evidence presented above showing that in some patients, definitive repair could be downscaled from a morbid surgical component separation to a simpler type of repair using the chemical components separation. Further studies are needed in the subgroup of patients with loss of domain, in which progressive preoperative pneumoperitoneum is combined with botulinum injections. In those patients a detailed and individualized anatomic study preoperatively, with the medial advancement gain by botox, might safely omit the preoperative pneumoperitoneum part, taking into consideration that progressive preoperative pneumoperitoneum is known to equally enlarge the hernia sac and the abdominal cavity. Therefore, a more personalized treatment of complex abdominal wall hernias will hopefully be the focus of future studies.

\section{Conflicts of Interest}

The Authors report no conflicts of interest or financial disclosures relevant to this paper.

\section{Authors' Contributions}

FS, DC: Conception and design of the study. FS, DC, AS: Acquisition of data, drafting the article. DC, TT: Drafting the article, revising it critically for important intellectual content. TT: Final approval of the version to be submitted.

\section{References}

1 Beadles CA, Meagher AD and Charles AG: Trends in emergent hernia repair in the United States. JAMA Surg 150(3): 194-200, 2015. PMID: 25564946. DOI: 10.1001/jamasurg.2014.1242

2 Slater NJ, Montgomery A, Berrevoet F, Carbonell AM, Chang A, Franklin M, Kercher KW, Lammers BJ, Parra-Davilla E, Roll S, Towfigh S, van Geffen E, Conze J and van Goor H: Criteria for definition of a complex abdominal wall hernia. Hernia 18(1): 717, 2014. PMID: 24150721. DOI: 10.1007/s10029-013-1168-6

3 Flum DR, Horvath $\mathrm{K}$ and Koepsell T: Have outcomes of incisional hernia repair improved with time? A population-based analysis. Ann Surg 237(1): 129-135, 2003. PMID: 12496540. DOI: $10.1097 / 00000658-200301000-00018$

4 Pauli EM and Rosen MJ: Open ventral hernia repair with component separation. Surg Clin North Am 93(5): 1111-1133, 2013. PMID: 24035078. DOI: 10.1016/j.suc.2013.06.010

5 Khansa I and Janis JE: The 4 Principles of complex abdominal wall reconstruction. Plast Reconstr Surg Glob Open 7(12): e2549, 2019. PMID: 32042542. DOI: 10.1097/GOX.0000000000002549 
6 Jensen KK, Oma E, Kjaer M, Jørgensen LN and Andersen JL: Histology and function of the rectus abdominis muscle in patients with incisional hernia. J Surg Res 253: 245-251, 2020. PMID: 32387572. DOI: 10.1016/j.jss.2020.03.033

7 Jensen KK, Kjaer M and Jorgensen LN: Abdominal muscle function and incisional hernia: a systematic review. Hernia 18(4): 481-486, 2014. PMID: 24728836. DOI: 10.1007/s10029014-1242-8

8 Jensen KK, Arnesen RB, Christensen JK, Bisgaard T and Jørgensen LN: Large incisional hernias increase in size. J Surg Res 244: 160-165, 2019. PMID: 31295649. DOI: 10.1016/ j.jss.2019.06.016

9 Jensen KK, Munim K, Kjaer M and Jorgensen LN: Abdominal wall reconstruction for incisional hernia optimizes truncal function and quality of life: a prospective controlled study. Ann Surg 265(6): 1235-1240, 2017. PMID: 27280505. DOI: 10.1097/ SLA.0000000000001827

10 Booth JH, Garvey PB, Baumann DP, Selber JC, Nguyen AT, Clemens MW, Liu J and Butler CE: Primary fascial closure with mesh reinforcement is superior to bridged mesh repair for abdominal wall reconstruction. J Am Coll Surg 217(6): 9991009, 2013. PMID: 24083910. DOI: 10.1016/j.jamcollsurg. 2013.08.015

11 Holihan JL, Askenasy EP, Greenberg JA, Keith JN, Martindale RG, Roth JS, Mo J, Ko TC, Kao LS, Liang MK and Ventral Hernia Outcome Collaboration Writing Group: Component separation $v s$. bridged repair for large ventral hernias: a multiinstitutional risk-adjusted comparison, systematic review, and meta-analysis. Surg Infect (Larchmt) 17(1): 17-26, 2016. PMID: 26375422. DOI: 10.1089/sur.2015.124

12 DuBay DA, Choi W, Urbanchek MG, Wang X, Adamson B, Dennis RG, Kuzon WM Jr and Franz MG: Incisional herniation induces decreased abdominal wall compliance via oblique muscle atrophy and fibrosis. Ann Surg 245(1): 140-146, 2007. PMID: 17197977. DOI: 10.1097/01.sla.0000251267.11012.85

13 Lien SC, Hu Y, Wollstein A, Franz MG, Patel SP, Kuzon WM $\mathrm{Jr}$ and Urbanchek MG: Contraction of abdominal wall muscles influences size and occurrence of incisional hernia. Surgery 158(1): 278-288, 2015. PMID: 25817097. DOI: 10.1016/j.surg.2015.01.023

14 den Hartog D, Eker HH, Tuinebreijer WE, Kleinrensink GJ, Stam $\mathrm{HJ}$ and Lange JF: Isokinetic strength of the trunk flexor muscles after surgical repair for incisional hernia. Hernia 14(3): 243-247, 2010. PMID: 20091329. DOI: 10.1007/s10029-010-0627-6

15 Lisiecki J, Kozlow JH, Agarwal S, Ranganathan K, Terjimanian MN, Rinkinen J, Brownley RC, Enchakalody B, Wang SC and Levi B: Abdominal wall dynamics after component separation hernia repair. J Surg Res 193(1): 497-503, 2015. PMID: 25201576. DOI: 10.1016/j.jss.2014.08.008

16 DiCocco JM, Magnotti LJ, Emmett KP, Zarzaur BL, Croce MA, Sharpe JP, Shahan CP, Jiao H, Goldberg SP and Fabian TC: Long-term follow-up of abdominal wall reconstruction after planned ventral hernia: a 15-year experience. J Am Coll Surg 210(5): 686-95, 695-8, 2010. PMID: 20421031. DOI: 10.1016/j.jamcollsurg.2009.12.034

17 Jankovic J: Botulinum toxin in clinical practice. J Neurol Neurosurg Psychiatry 75(7): 951-957, 2004. PMID: 15201348. DOI: $10.1136 /$ jnnp.2003.034702

18 Zielinski MD, Goussous N, Schiller HJ and Jenkins D: Chemical components separation with botulinum toxin A: a novel technique to improve primary fascial closure rates of the open abdomen. Hernia 17(1): 101-107, 2013. PMID: 23001400. DOI: 10.1007/s 10029-012-0995-1

19 Ibarra-Hurtado TR, Nuño-Guzmán CM, Miranda-Díaz AG, Troyo-Sanromán R, Navarro-Ibarra R and Bravo-Cuéllar L: Effect of botulinum toxin type $\mathrm{A}$ in lateral abdominal wall muscles thickness and length of patients with midline incisional hernia secondary to open abdomen management. Hernia 18(5): 647-652, 2014. PMID: 25033942. DOI: 10.1007/s10029-014$1280-2$

20 Zendejas B, Khasawneh MA, Srvantstyan B, Jenkins DH, Schiller HJ and Zielinski MD: Outcomes of chemical component paralysis using botulinum toxin for incisional hernia repairs. World J Surg 37(12): 2830-2837, 2013. PMID: 24081529. DOI: 10.1007/s00268-013-2211-6

21 Muysoms FE, Miserez M, Berrevoet F, Campanelli G, Champault GG, Chelala E, Dietz UA, Eker HH, El Nakadi I, Hauters P, Hidalgo Pascual M, Hoeferlin A, Klinge U, Montgomery A, Simmermacher RK, Simons MP, Smietański M, Sommeling C, Tollens T, Vierendeels $\mathrm{T}$ and Kingsnorth A: Classification of primary and incisional abdominal wall hernias. Hernia 13(4): 407-414, 2009. PMID: 19495920. DOI: 10.1007/s10029-009-0518-x

22 Tanaka EY, Yoo JH, Rodrigues AJ Jr, Utiyama EM, Birolini D and Rasslan S: A computerized tomography scan method for calculating the hernia sac and abdominal cavity volume in complex large incisional hernia with loss of domain. Hernia 14(1): 63-69, 2010. PMID: 19756913. DOI: 10.1007/s10029-009-0560-8

23 Sabbagh C, Dumont F, Robert B, Badaoui R, Verhaeghe P and Regimbeau JM: Peritoneal volume is predictive of tension-free fascia closure of large incisional hernias with loss of domain: a prospective study. Hernia 15(5): 559-565, 2011. PMID: 21584816. DOI: 10.1007/s10029-011-0832-y

24 Toniato A, Pagetta C, Bernante P, Piotto A and Pelizzo MR: Incisional hernia treatment with progressive pneumoperitoneum and retromuscular prosthetic hernioplasty. Langenbecks Arch Surg 387(5-6): 246-248, 2002. PMID: 12410362. DOI: 10.1007/s00423-002-0316-8

25 Mayagoitia JC, Suárez D, Arenas JC and Díaz de León V: Preoperative progressive pneumoperitoneum in patients with abdominal-wall hernias. Hernia 10(3): 213-217, 2006. PMID: 16261394. DOI: 10.1007/s10029-005-0040-8

26 Dumont F, Fuks D, Verhaeghe P, Brehant O, Sabbagh C, Riboulot M, Yzet $\mathrm{T}$ and Regimbeau JM: Progressive pneumoperitoneum increases the length of abdominal muscles. Hernia 13(2): 183-187, 2009. PMID: 18949443. DOI: 10.1007/ s10029-008-0436-3

27 Sabbagh C, Dumont F, Fuks D, Yzet T, Verhaeghe P and Regimbeau JM: Progressive preoperative pneumoperitoneum preparation (the Goni Moreno protocol) prior to large incisional hernia surgery: volumetric, respiratory and clinical impacts. A prospective study. Hernia 16(1): 33-40, 2012. PMID: 21773758. DOI: $10.1007 / \mathrm{s} 10029-011-0849-2$

28 Bueno-Lledó J, Torregrosa A, Jiménez R and Pastor PG: Preoperative combination of progressive pneumoperitoneum and botulinum toxin type A in patients with loss of domain hernia. Surg Endosc 32(8): 3599-3608, 2018. PMID: 29450631. DOI: 10.1007/s00464-018-6089-0

29 Rosen MJ: Atlas of abdominal wall reconstruction, $2^{\text {nd }}$ edition. Elsevier, pp. 82-93, 2016 
30 Sneiders D, Yurtkap Y, Kroese LF, Jeekel J, Muysoms FE, Kleinrensink GJ and Lange JF: Anatomical study comparing medialization after Rives-Stoppa, anterior component separation, and posterior component separation. Surgery 165(5): 996-1002, 2019. PMID: 30685071. DOI: 10.1016/j.surg.2018.11.013

31 Maloney SR, Schlosser KA, Prasad T, Kasten KR, Gersin KS, Colavita PD, Kercher KW, Augenstein VA and Heniford BT: Twelve years of component separation technique in abdominal wall reconstruction. Surgery 166(4): 435-444, 2019. PMID: 31358348. DOI: 10.1016/j.surg.2019.05.043

32 Maloney SR, Augenstein VA, Oma E, Schlosser KA, Prasad T, Kercher KW, Sing RF, Colavita PD and Heniford BT: The use of component separation during abdominal wall reconstruction in contaminated fields: A case-control analysis. Am J Surg 218(6): 1096-1101, 2019. PMID: 31630827. DOI: 10.1016/ j.amjsurg.2019.10.019

33 Docimo S Jr, Spaniolas K, Svestka M, Bates AT, Sbayi S, Schnur J, Talamini M and Pryor AD: Increased incidence of surgical site infection with a body mass index $\geq 35 \mathrm{~kg} / \mathrm{m}^{2}$ following abdominal wall reconstruction with open component separation. Surg Endosc 33(8): 2503-2507, 2019. PMID: 30350101. DOI: 10.1007/s00464-018-6538-9

34 Giurgius M, Bendure L, Davenport DL and Roth JS: The endoscopic component separation technique for hernia repair results in reduced morbidity compared to the open component separation technique. Hernia 16(1): 47-51, 2012. PMID: 21833851. DOI: 10.1007/s10029-011-0866-1

35 DelMauro MA and Moon VA: Obesity and the abdominal wall vasculature: correlating BMI with perforator anatomy. J Reconstr Microsurg 36(6): 438-444, 2020. PMID: 32088919. DOI: $10.1055 / \mathrm{s}-0040-1702176$

36 Maloney SR, Schlosser KA, Prasad T, Colavita PD, Kercher $\mathrm{KW}$, Augenstein VA and Heniford BT: The impact of component separation technique versus no component separation technique on complications and quality of life in the repair of large ventral hernias. Surg Endosc 34(2): 981-987, 2020. PMID: 31218419. DOI: $10.1007 / \mathrm{s} 00464-019-06892-\mathrm{x}$

37 Bueno-Lledó J, Martinez-Hoed J, Torregrosa-Gallud A, MenéndezJiménez $M$ and Pous-Serrano S: Botulinum toxin to avoid component separation in midline large hernias. Surgery 168(3): 543549, 2020. PMID: 32576404. DOI: 10.1016/j.surg.2020.04.050

38 Deerenberg EB, Elhage SA, Shao JM, Lopez R, Raible RJ, Kercher KW, Colavita PD, Augenstein VA and Heniford BT: The effects of preoperative botulinum toxin A injection on abdominal wall reconstruction. J Surg Res 260: 251-258, 2021. PMID: 33360691. DOI: 10.1016/j.jss.2020.10.028

39 Deerenberg EB, Shao JM, Elhage SA, Lopez R, Ayuso SA, Augenstein VA and Heniford BT: Preoperative botulinum toxin A injection in complex abdominal wall reconstruction- a propensity-scored matched study. Am J Surg, 2021. PMID: 33478721. DOI: 10.1016/j.amjsurg.2021.01.010

40 Nielsen MØ, Bjerg J, Dorfelt A, Jørgensen LN and Jensen KK: Short-term safety of preoperative administration of botulinum toxin A for the treatment of large ventral hernia with loss of domain. Hernia 24(2): 295-299, 2020. PMID: 31041556. DOI: 10.1007/s10029-019-01957-1

41 Deerenberg EB, Elhage SA, Raible RJ, Shao JM, Augenstein VA, Heniford BT and Lopez R: Image-guided botulinum toxin injection in the lateral abdominal wall prior to abdominal wall reconstruction surgery: review of techniques and results. Skeletal
Radiol 50(1): 1-7, 2021. PMID: 32621063. DOI: 10.1007/ s00256-020-03533-6

42 Elstner KE, Read JW, Saunders J, Cosman PH, RodriguezAcevedo O, Jacombs ASW, Martins RT and Ibrahim N: Selective muscle botulinum toxin A component paralysis in complex ventral hernia repair. Hernia 24(2): 287-293, 2020. PMID: 30949893. DOI: 10.1007/s10029-019-01939-3

43 Catalán-Garza V, Peña-Soria MJ, Sáez-Carlin P, Cabeza-Gómez JJ, García-Fernández A and Torres-García AJ: Long-term results of botulinum toxin type A in complex abdominal wall repair and review of the literature. Updates Surg 72(4): 1201-1206, 2020. PMID: 32382958. DOI: 10.1007/s13304-020-00775-w

44 Wegdam JA, de Vries Reilingh TS, Bouvy ND and Nienhuijs SW: Prehabilitation of complex ventral hernia patients with Botulinum: a systematic review of the quantifiable effects of Botulinum. Hernia, 2020. PMID: 33215244. DOI: 10.1007/ s10029-020-02333-0

45 Elstner KE, Read JW, Rodriguez-Acevedo O, Cosman PH, Dardano AN, Jacombs AS, Edye M, Zea A, Boesel T, Mikami DJ and Ibrahim N: Preoperative chemical component relaxation using Botulinum toxin A: enabling laparoscopic repair of complex ventral hernia. Surg Endosc 31(2): 761-768, 2017. PMID: 27351658. DOI: 10.1007/s00464-016-5030-7

46 De Silva GS, Krpata DM, Hicks CW, Criss CN, Gao Y, Rosen MJ and Novitsky YW: Comparative radiographic analysis of changes in the abdominal wall musculature morphology after open posterior component separation or bridging laparoscopic ventral hernia repair. J Am Coll Surg 218(3): 353-357, 2014. PMID: 24468226. DOI: 10.1016/j.jamcollsurg.2013.11.014

47 Hodgkinson JD, Leo CA, Maeda Y, Bassett P, Oke SM, Vaizey CJ and Warusavitarne J: A meta-analysis comparing open anterior component separation with posterior component separation and transversus abdominis release in the repair of midline ventral hernias. Hernia 22(4): 617-626, 2018. PMID: 29516294. DOI: 10.1007/s10029-018-1757-5

48 Cunha LAC, Cançado ARS, Silveira CAB, Pinheiro VPSF and Neto OMS: Management of complex hernias with loss of domain using daily and fractioned preoperative progressive pneumoperitoneum: a retrospective single-center cohort study. Hernia, 2020. PMID: 32926260. DOI: 10.1007/s10029-020-02298-0

49 Xu Z, Asman AJ, Baucom RB, Abramson RG, Poulose BK and Landman BA: Quantitative CT imaging of ventral hernias: preliminary validation of an anatomical labeling protocol. PLoS One 10(10): e0141671, 2015. PMID: 26509450. DOI: 10.1371/ journal.pone.0141671

50 Zhang Q, Fu X, He K, Chen H, Zheng Y, Feng X and Yao Q: A new technique for the $3 \mathrm{D}$ reconstruction of the incisional hernia: A pilot study. Clin Imaging 67: 91-94, 2020. PMID: 32531694. DOI: $10.1016 /$ j.clinimag.2020.05.023

51 Majumder A, Miller HJ, Del Campo LM, Soltanian H and Novitsky YW: Assessment of myofascial medialization following posterior component separation via transversus abdominis muscle release in a cadaveric model. Hernia 22(4): 637-644, 2018. PMID: 29713832. DOI: 10.1007/s10029-018-1771-7

Received March 30, 2021

Revised April 18, 2021

Accepted April 22, 2021 